Archives de sciences sociales des religions

128 | octobre - décembre 2004

Varia

\title{
Moussa Khedimellah (éd.), Religiosités
}

contemporaines

Socio-anthropologie, $n^{\circ}$ 10, 2001, 136 p. (illustr.)

Véronique Altglas

\section{(2) OpenEdition}

\section{Journals}

Édition électronique

URL : http://journals.openedition.org/assr/2598

DOI : 10.4000/assr.2598

ISSN : $1777-5825$

Éditeur

Éditions de l'EHESS

Édition imprimée

Date de publication : 1 octobre 2004

Pagination : 53-158

ISBN : 2-222-96754-6

ISSN : 0335-5985

\section{Référence électronique}

Véronique Altglas, « Moussa Khedimellah (éd.), Religiosités contemporaines 》, Archives de sciences sociales des religions [En ligne], 128 | octobre - décembre 2004, document 128.70, mis en ligne le 18 novembre 2005, consulté le 24 septembre 2020. URL : http://journals.openedition.org/assr/2598 ; DOI : https://doi.org/10.4000/assr.2598 
construction et la reconnaissance du charisme. $\mathrm{Au}$ contraire, la reconnaissance du charisme serait basée sur des processus non pas culturels mais cognitifs et universaux, l'émotion suscitée par les rituels et les situations d'interaction, ainsi que les concepts religieux évoqueraient de puissantes et fondamentales formes de pensée intuitive.

Ainsi, axé sur des processus cognitifs et communicationnels, le charisme dépendrait fondamentalement de mécanismes cognitifs et de processus interactionnels «pan-humains».

Véronique Altglas.

128.70

KHEDIMELLAH (Moussa), éd.

Religiosités contemporaines. Socio-anthropologie, $\mathrm{n}^{\mathrm{o}} 10,2001,136$ p. (illustr.).

Socio-Anthropologie présente des travaux qui s'inscrivent dans une démarche interdisciplinaire et qui s'intéressent aux phénomènes de déstructuration et de recomposition au sein des sociétés contemporaines. Le numéro en question rassemble des contributions prenant pour objet les mutations du religieux dans différentes aires culturelles. Sur le terrain français, M. K. étudie la conversion de jeunes au mouvement Tabligh, L. Podselver analyse la transposition d'un pèlerinage juif tunisien à Sarcelles et S. CogatDroulez prend pour objet les guérisons miraculeuses associées au pèlerinage de Lourdes. Deux articles illustrent les dynamiques de recompositions religieuses en Amérique du Sud: S. Pédron-Colombani traite de la diffusion du pentecôtisme au Guatemala et J.-P. Goulard des mouvements messianiques amazoniens. Enfin, le renouvellement du fait religieux et le déplacement de ses frontières sont illustrés par l'idéologie du New Age (M.-J. Ferreux), et par le culte autour du chanteur Elvis Presley qu'analyse G. Segré.

L'hétérogénéité des aires culturelles et des sujets abordés (conversion, émergence et diffusion de mouvements religieux, réactualisation d'anciennes pratiques...) met en perspective, sous différents angles, les dynamiques de rupture et de continuité, de syncrétisme et de mutation qui caractérisent les mondes religieux contemporains. Ainsi, la conversion au Tabligh semble réorganiser une vie éclatée et reconstruire une identité pour une jeunesse défavorisée et ostracisée, tandis que la réactualisation à Sarcelles du pèlerinage d'El Hamma, résultant de l'atomisation des références religieuses, permet d'affirmer un lien communautaire et religieux, tout en faisant de l'événement un objet de consommation, un loisir qui voudrait avoir du sens. La diffusion de mouvements pentecôtistes au Guatemala et de messianismes en Amazonie suscite de profondes mutations de l'organisation sociale et familiale, elle crée de nouveaux liens communautaires et de nouvelles formes d'affirmations identitaires. Introduisant de nouvelles pratiques tout en s'adaptant aux croyances et aux pratiques anciennes, ces religions opèrent des synthèses avec les mythes fondateurs et les formes religieuses traditionnelles. Les sociétés occidentales sont également le terrain de transformations et de déplacements des frontières du religieux. Ainsi, le New Age, apparu dans le contexte de la contre-culture, est un courant pluriel et diffus. Il s'organise toutefois autour de l'aspiration à construire un monde nouveau grâce à la transformation individuelle, à laquelle participent des techniques de développement personnel diverses. Le New Age élabore selon l'auteur un ésotérisme mêlant références orientales et occidentales, réactualise d'anciennes traditions, et propose de nouvelles pratiques. Il dénote enfin un intérêt pour le retour à la nature. À l'instar de l'introduction de la validation scientifique des guérisons miraculeuses de Lourdes, le New Age illustre l'interpénétration des ressources et des univers religieux, scientifiques ou psychologiques. Enfin, le culte qui s'est développé autour du chanteur américain Elvis Presley s'inscrirait également dans le cadre de la mutation des formes du croire. Il peut se comprendre comme la formation d'une fraternité élective autour d'une figure charismatique sacralisée. Cette fraternité élective se serait ensuite transformée en communauté émotionnelle après la mort du King : elle élabore une identité et une mémoire collective, fait appel à « l'esprit d'Elvis » et à des valeurs communes, se rend en pèlerinage dans la demeure de la star disparue.

Ces études mettent en perspective les questions de territorialisation du religieux, de la mobilité des croyants et de la transposition des pratiques. Elles suscitent également des réflexions quant à la diffusion transnationale et à l'adaptation locale des mouvements religieux, qu'il s'agisse du Tabligh, mouvement missionnaire né dans la communauté musulmane de l'Inde, répandu au cours du $\mathrm{XX}^{\mathrm{e}}$ siècle dans les pays musulmans puis en Occident, ou de la diffusion transnationale du pentecôtisme au Guatemala, s'adaptant aux traditions locales pré-existantes. En Amazonie, la conversion des Ticuna aux mouvements évangéliques et cruzistes, implique un rapport complexe et dynamique entre des mouvements religieux transfrontaliers et leur inscription territoriale, locale, au sein des villages. De son côté, l'affinité du réseau internet avec l'idéologie New 
Age, développant la vision holiste d'un monde global, participerait au développement d'un monde «inter-relié ».

Véronique Altglas.

\subsection{1}

KOUNKOU (Dominique), éd.

Les Nouvelles formes du sentiment religieux : un défi pour la laïcité moderne ? Paris, l'Harmattan, 2003, 310 p.

Cet ouvrage réunit les Actes du colloque national organisé par le Centre de formation et d'études judiciaires, tenu à la Maison du Barreau en janvier 2003. Il réunit des spécialistes du droit, tel Jacques Robert, des avocats, dont Jean-Marc Florand, Olivier-Louis Séguy, Philippe Gast, des sociologues, tels que Raphaël Liogier, Régis Dericquebourg ou Jean Baubérot, ou encore l'ethnologue Maurice Duval. La plupart des intervenants sont engagés dans la défense des nouveaux mouvements religieux, ou cherchent, en tout cas, à faire entendre une voix différente de celle des associations antisectes. On y commente bien sûr la loi 1905, celle visant les sectes de 2001. On réfléchit sur la laïcité telle que pratiquée aujourd'hui. On y critique la discrimination opérée par l'État vis-à-vis des minorités religieuses. Quelques éclairages juridiques paraissent utiles et des réflexions nouvelles percent ici ou là, même si l'ensemble a un goût de déjà entendu. L'ouvrage intéressera ceux encore peu avertis de la polémique existant autour de la politique française en matière de sectes.

\section{Nathalie Luca.}

La Grande aventure du monachisme entre Orient et Occident. Paris, Lethielleux, 2002, 272 p. (index, cartes, illustr.).

Ce livre, à la fois chronologique et géographique, touche le long terme historique et les grands espaces traditionnels et plus récents du monachisme. Les auteurs, issus pour l'essentiel du monde monastique méditerranéen, évoquent, sans surprise, l'universalité du phénomène monastique, ses origines dans le monde chrétien, son développement en Orient et en Occident jusqu'au Moyen Âge avant de consacrer deux chapitres, l'un aux monachismes orientaux (de l'époque médiévale au $\mathrm{XX}^{\mathrm{e}}$ siècle) et à ses spécificités régionales et l'autre, consacré au monachisme occidental, de saint Anselme à Charles de Foucauld, avant de terminer par une série d'évocations rapides du monachisme contemporain en Amérique, en Afrique, en Asie et en Océanie. Cet ouvrage ne se fait guère l'écho de l'historiographie récente, reproduit des schémas traditionnels apologétiques, voire même caricaturaux lorsqu'il évoque Rancé par exemple et la querelle des études, passe sous silence la restauration bénédictine française et européenne au XIX ${ }^{\mathrm{e}}$ siècle et, ce qui est plus choquant, assimile l'assassinat récent des trappistes en Algérie aux difficultés que le monachisme connut dans l'histoire de l'expansion de l'islam (p. 111). On regrettera aussi des approximations dans la traduction: «mouvement monarchique » pour mouvement monastique (p. 146), vocation «monachique» (p. 18), ou encore "Maurins » pour Mauristes (pp. 239 et 241). Si les illustrations, de bonne qualité, restent peu originales, la cartographie apparaît plus intéressante.

Daniel-Odon Hurel.

La Bible au Moyen Âge. Paris, Picard, 2003, 247 p. (bibliogr., index, illustr.) (coll. «Les Médiévistes français », 3).

Sous le titre La Bible au Moyen Âge, G.L., maître de conférences au Collège de France, présente un dossier d'articles (publiés entre 1984 et 2001) sur la place des Écritures dans la littérature médiévale. Ces contributions, regroupées en trois chapitres à la délimitation quelque peu artificielle (« Lire », «User » et « Gloser »), portent à la fois sur des questions d'ensemble (comme l'histoire de l'exégèse biblique) et sur des dossiers plus circonscrits : la Bible de la Réforme ecclésiastique (XI' siècle), l'Apocalypse au Moyen Âge... La grande majorité de ces articles traitent effectivement du thème signalé par le titre et développé dans l'avant-propos, mais on note, comme dans tout recueil de ce type, des chapitres quelque peu hors sujet (ainsi le chapitre 5, sur «la dédicace de l'Église abbatiale de Saint-Germain d'Auxerre ", ou le chapitre 9, sur « les courants spirituels dans la chrétienté occidentale à l'aube du concile de Plaisance »); leur suppression aurait peut-être permis à cet ouvrage d'être composé dans un corps plus gros, rendant sa lecture moins pénible pour les yeux.

Ce recueil d'articles forme un ensemble très riche sur un sujet longtemps négligé par les médiévistes. Il démontre de façon magistrale la fausseté de nombreuses idées reçues, soulignant à quel point la Bible était lue au Moyen Âge (pas seulement par les clercs) et formait le ciment de la société médiévale; plusieurs chapitres de la deuxième partie s'attardent ainsi sur le rôle joué 